\title{
AS BASES NEUROBIOLÓGICAS DA APRENDIZAGEM NO CONTEXTO DA INVESTIGAÇÃO TEMÁTICA FREIRIANA
}

\author{
THE NEUROBIOLOGICAL BASE OF LEARNING IN CONTEXT OF THE FREIRE THEMATIC RESEARCH
}

LAS BASES NEUROBIOLÓGICAS DEL APRENDIZAJE EN EL CONTEXTO DE LA INVESTIGACIÓN TEMÁTICA FREIRIANA

Diana Paula Salomão de Freitas ${ }^{1}$

Cezar Soares Motta ${ }^{2}$

Pâmela Billig Mello-Carpes ${ }^{3}$

Resumo No artigo, defendemos o argumento de que a investigação temática proposta por Freire, ao estreitar a relação conteúdo-cotidiano, favorece a reconstrução do conhecimento, tendo como base as memórias sociais e culturais. Essas memórias, transformadas em estímulos emocionalmente competentes, propiciam uma ação docente que oportuniza a ampliação de saberes e engramas e, consequentemente, capacita os aprendentes para a transformação da realidade. Para tanto, apresentamos as ideias freirianas sobre a necessidade ontológica dos humanos de desenvolverem a consciência crítica acerca de suas situações existenciais, com base na investigação temática. Nesse processo, o que se almeja é a percepção existencial dos sujeitos, de modo que, tomando distância da situação em que se encontram, possam elaborá-la como uma imagem, quadro ou slide, sobre o qual se pode problematizar, discutir e contestar para transformar. Na sequência dessa atitude educativa, discutimos as bases neurobiológicas, ou seja, como o cérebro interpreta, compreende e apreende as informações dos contextos investigados e apresentamos alguns entendimentos sobre estímulos emocionalmente competentes e o processo de aprendizagem.

Palavras-chave educação; Paulo Freire; estímulos emocionalmente competentes; neurociências.
Abstract In this article, we defend the argument that the research topic proposed by Freire, when narrowing the content-everyday life relationship, fosters knowledge reconstruction based on social and cultural memories. These memories, turned into emotionally competent stimuli, provide a teaching action that favors the expansion of knowledge and engrams and, thus, enables learners to transform reality. Therefore, we present Freirian ideas about the ontological need humans have to develop critical awareness about their existential situations, based on thematic research. In this process, the aim is the existential awareness of the subjects, so that, distancing themselves from the situation they are in, they can develop it as an image, picture or slide on which to discuss, argue and challenge to transform. Following this educational attitude, we discuss the neurobiological bases, i.e. how the brain interprets, understands and grasps the information from the investigated contexts and present a few insights on emotionally appropriate stimuli and the learning process.

Keywords education; Paulo Freire; emotionally appropriate stimuli; neurosciences. 


\section{O desenvolvimento da consciência crítica para compreender a necessidade da investigação temática freiriana}

No capítulo três do livro Pedagogia do oprimido, Freire (2011) trata especificamente da justificativa, da explicação e de exemplos do que denomina investigação temática (IT), tema que aprofundaremos no próximo item deste texto. A IT, segundo o autor, é o processo de busca pelo conteúdo programático, para desenvolvimento de um processo educativo humanista, o qual Freire defende ser o processo que permite "a tomada de consciência de nossa plena humanidade, como condição e obrigação: como situação e projeto" (Furter apud Freire, 2011, p. 117) de "superação das situações-limite em que os homens se acham quase coisificados" (Freire, 2011, p. 131).

Para explicitarmos o significado da IT, é necessária uma breve retomada do que o autor defende como desenvolvimento da consciência crítica, necessidade ontológica em que está a possibilidade de homens e mulheres de serem mais. Especificidade que garante, na historicidade das situações, alternativas para o que está posto; possibilidades para mudanças. Nas palavras do autor:

É por estarmos sendo este ser em permanente procura, curioso, "tomando distância" de si mesmo e da vida que porta; é por estarmos sendo este ser dado à aventura e à "paixão de conhecer", para o que se faz indispensável a liberdade que, constituindo-se na luta por ela, só é possível porque, "programados", não somos, porém, determinados; é por estarmos sendo assim que vimos nos vocacionando para a humanização e que temos, na desumanização, fato concreto na história, a distorção da vocação. Jamais, porém, outra vocação humana, nem uma nem outra, humanização e desumanização, são destino certo, dado, sina ou fado. Por isso mesmo é que uma é vocação e outra, distorção da vocação.

É importante insistir que, ao falar do "ser mais" ou da humanização como vocação ontológica do ser humano, não estou caindo em nenhuma posição fundamentalista, de resto, sempre conservadora. Daí que insista também em que esta "vocação", em lugar do ser algo a priori da história é, pelo contrário, algo que se vem constituindo na história. Por outro lado, a briga por ela, os meios de levá-la a cabo, históricos também, além de variar de espaço-tempo a espaço-tempo, demandam, indiscutivelmente, a assunção de uma utopia. A utopia, porém, não seria possível se faltasse a ela o gosto da liberdade, embutido na vocação para a humanização. Se faltasse também a esperança sem a qual não lutamos (Freire, 1997, p. 51).

A vocação ontológica, da qual fala Freire, também pode ser desenvolvida a partir dos processos educativos, por meio da educação problematizadora, contrapondo-se às corriqueiras práticas da educação bancária adestradora, que submete ao aprendente uma espécie de anestesia do pensar crítico. Seres 
criadores, inventores e imaginativos que somos, devemos participar de espaços que se proponham pensar sobre a realidade em que estamos, possibilitando perceber as diversas condições existentes, das dinâmicas que podem ser alteradas a favor dos sujeitos. Esse é o sentido da educação escolar que defendemos no artigo e que atribuímos à fala de Freire.

A partir da educação problematizadora, Freire é considerado educador que, ao pensar a existência humana, "existencia seu pensamento numa pedagogia em que o esforço totalizador da práxis humana busca, na intencionalidade desta, retotalizar-se como "prática da liberdade"' (Fiori, 2011, p. 11). Liberdade esta que o autor atribui à consciência humana, que "só encontrará adequada expressão numa pedagogia em que o oprimido tenha condições de, reflexivamente, descobrir-se e conquistar-se como sujeito de sua própria destinação histórica" (Fiori, 2011, p. 11) - sendo os oprimidos os homens e as mulheres proibidos de sua condição de ser mais; e opressores, mulheres e homens que participam da dinâmica estrutural que conduz à dominação de consciências.

Com essa apresentação, frisamos que a pedagogia do oprimido, anunciada por Freire, é o difícil e imprescindível aprendizado apregoado pelo professor Ernani Maria Fiori, que é quem faz o prefácio do livro. Aprendizado que diz respeito à libertação de consciências que, ao fazerem-se crítica, manifestam a capacidade transformadora e criadora das mulheres e dos homens. Consciência que, segundo o autor, é

essa misteriosa e contraditória capacidade que tem o homem de distanciar-se das coisas para fazê-las presentes, imediatamente presentes. (...) É um comportar-se do homem frente ao meio que o envolve, transformando-o em mundo humano (Freire, 2011, p. 77).

Nesse sentido, o autor nos apresenta uma visão dialética de se pensar a consciência, recusando a ideia falsa de compreendermos a consciência como puro reflexo da objetividade material ou que tenha poder determinante sobre a realidade concreta. Em suas palavras:

Enquanto para as posições dogmáticas, mecanicistas, a consciência, que venho chamando de crítica, toma forma como uma espécie de epifenômeno, como resultado automático e mecânico de mudanças estruturais, para a dialética, a importância da consciência está em que, não sendo a fazedora da realidade, não é, por outro lado, como já disse, puro reflexo seu. É exatamente aí que se coloca a importância fundamental da educação enquanto ato de conhecimento, não só de conteúdos, mas da razão de ser dos fatos econômicos, sociais, políticos, ideológicos, históricos, que explicam o maior ou menor grau de "interdição do corpo" consciente, a que estejamos submetidos (Freire, 1997, p. 53). 
Nesse contexto, a verdadeira conscientização da realidade não consiste apenas no seu desvelamento, mas na sua transformação, por isso o sonho é propulsor imprescindível dessa transformação. Assim, o autor acentua a necessidade de o educador se familiarizar com o contexto dos grupos com que trabalha, a fim de entender sua leitura do mundo, seu modo de construir cultura; de resistir às condições proibitivas do desenvolvimento de sua vocação ontológica. Desde aí o educador terá condições de 'capturar' as situações para problematizá-las e, no lugar da consciência conformada, produzir espaço para construção da consciência crítica, que pode então contribuir para a transformação da realidade existente.

No momento em que a percepção crítica se instaura, na ação mesma, se desenvolve um clima de esperança e confiança que leva os homens a se empenharem na superação das "situações-limite" (Freire, 2011, p. 126).

\section{O processo de investigação temática}

Diante do que apresentamos, da necessidade do desenvolvimento da consciência crítica em processos educativos humanistas, libertadores de consciência, abordaremos o método de conhecer a realidade do educando para o desenvolvimento de sua consciência crítica. Esse processo é iniciado pelo que Freire denomina investigação temática, "um esforço comum de consciência da realidade e de autoconsciência, que a inscreve como ponto de partida do processo educativo, ou da ação cultural de caráter libertador" (Freire, 2011, p. 138). É o esforço de propor aos indivíduos dimensões significativas de sua realidade, cuja análise crítica lhes possibilite reconhecer a interação das partes.

A IT é o ponto de partida de um processo educativo conscientizador, inclusive no processo de busca e elaboração das situações cotidianas de quem aprende. Esse processo, ao mesmo tempo que apreende temas que podem gerar outros temas para continuidade do trabalho, proporciona àquele que investiga a tomada de consciência das situações em que se encontra. É investigação que pretende ainda pesquisar o pensamento-linguagem que as mulheres e os homens têm da realidade; "os níveis de sua percepção desta realidade, a sua visão do mundo, em que se encontram envolvidos seus 'temas geradores'" (Freire, 2011, p. 122). Nas palavras do próprio Freire (2011):

A investigação temática, repitamos, envolve a investigação do próprio pensar do povo. Pensar que não se dá fora dos homens, nem num homem só, nem no vazio, mas nos homens e entre os homens, e sempre referido à realidade (Freire, 2011, p. 140). 
Esse processo centra-se no (re)conhecimento e busca da situação dos homens e das mulheres a quem o educador se dirige, na medida em que: "Os homens são porque estão em situação. E serão tanto mais quanto não só pensem criticamente sobre sua forma de estar, mas criticamente atuem sobre a situação em que estão" (Freire, 2011, p. 141).

Assim, para trabalhar um conteúdo programático contextualizado e relacionado com o educando, é importante que o educador proponha as situações dos sujeitos,

através de certas contradições básicas, sua situação existencial, concreta, presente, como problema que, por sua vez, o desafia e, assim, lhe exige resposta, não só no nível intelectual, mas no nível da ação (Freire, 2011, p. 120).

Freire pontua etapas para a investigação temática, em que, no processo, localiza-se o momento para codificar as situações em quadros que serão, dialogicamente, problematizados pelos aprendentes. Nessa proposta pedagógica, atribui-se um papel elementar à escolha coletiva do conteúdo programático, que não é eleito exclusivamente pelos educadores. São as etapas:

1 - Delimitação da área em que uma equipe multidisciplinar, de modo dialógico, vai trabalhar a pedagogia problematizadora.

2 - Convite a um número significativo de pessoas que aceite uma conversa informal com os pesquisadores, membros da equipe multidisciplinar, que lhes falarão do objetivo de sua presença na área. Desde aí, estimulam-se os presentes para que, dentre eles, apareçam os que queiram participar diretamente do processo de investigação como seus auxiliares (cuja presença ativa é muito importante para a investigação).

3 - Visitações (em horário comercial) na área de estudo, com "atitudes compreensivas em face do que observam" (Freire, 2011, p. 144). Visita após visita, busca-se a descrição das situações, registradas em diário (que posteriormente constituirão relatórios a serem discutidos no grupo). Ora se registra a visão crítica e observadora diretamente de quem pesquisa, ora se realizam diálogos informais com os habitantes da área de estudo (Freire, 2011). Nesse momento, observa-se o comportamento dos moradores nas cerimônias religiosas, em suas casas ou nas reuniões de associação popular, de modo a observar: suas expressões; sua linguagem; suas palavras; sua forma de construir seu pensamento; as relações entre as diretorias e os sócios; o papel que desempenham as mulheres e os jovens; os momentos de lazer; e as manifestações em torno das relações matrimoniais e de pais-filhos.

4 - Realização de seminários de avaliação, se possível, na área de trabalho, para que todos possam participar. Momento de 'descodificação' ao vivo, em que todos expõem como perceberam e sentiram esse ou aquele momento, aquela observação registrada, codificada. 
5 - Em equipe, será feita a escolha de algumas das contradições; elaboração das contradições em forma de pinturas ou fotografias, que serão codificações para a investigação; representação das situações conhecidas pelos indivíduos, cuja temática é conhecida por eles e deve refletir uma situação existencial, "aspectos concretos de suas necessidades sentidas" (Freire, 2011, p. 154). Não é possível propor representações de realidades estranhas. "As codificações não são slogans, são objetos cognoscíveis, desafios sobre que deve incidir a reflexão crítica dos sujeitos descodificadores" (Freire, 2011, p. 151). 6 - Percepção da percepção anterior: descodificação. Momento em que os indivíduos, exteriorizando sua temática, explicitam sua consciência real (Goldman, 1969)4 da realidade. Segundo Freire (2011):

Promovendo a percepção da percepção anterior e o conhecimento do conhecimento anterior, a descodificação, desta forma, promove o surgimento de nova percepção e o desenvolvimento de novo conhecimento. A nova percepção e o novo conhecimento, cuja formação já começa nesta etapa da investigação, se prolongam, sistematica $\neg$ mente, na implantação do plano educativo, transformando o "inédito viável" na "ação editanda", com a superação da "consciência real" pela "consciência máxima possível" (Freire, 2011, p. 153).

7 - Gravação do processo de decodificação para ser posteriormente analisado pela equipe multidisciplinar, juntamente com os auxiliares de investigação, que serão os "retificadores e ratificadores da interpretação que fazem estes dos achados da investigação" (Freire, 2011, p. 156). Sugere-se, ainda, a participação de um psicólogo e um sociólogo, cuja tarefa é registrar reações mais significativas ou aparentemente pouco significativas dos sujeitos descodificadores.

Momento em que os participantes vão extrojetando, pela força catártica da metodologia, uma série de sentimentos, de opiniões, de si, do mundo e dos outros, que possivelmente não extrojetariam em circunstâncias diferentes (Freire, 2011, p. 157).

8 - Estudo sistemático e interdisciplinar dos achados na IT; num primeiro instante ouvindo gravação por gravação e, também, estudando as notas fixadas pelo psicólogo e pelo sociólogo. Esses temas devem ser classificados num quadro geral e, desde aí, receber enfoques da antropologia, da psicologia social, da filosofia etc. Cada especialista deve propor à equipe um projeto de 'redução' de seu tema e observar também a necessidade de apresentar alguns temas fundamentais que não foram sugeridos, o que Freire (2011) chama de 'temas dobradiças', pois facilitam a compreensão entre os temas no conjunto da unidade programática.

Explicitadas as etapas da IT, foquemo-nos a seguir na importância de os aprendentes participarem do contexto em que são produzidos os objetos 
cognoscíveis que serão estudados, em vez de apenas discutirem os conteúdos recortados da realidade estudada, fundamentando-nos nos aspectos neurobiológicos.

\section{A importância da aprendizagem focada no contexto do aprendente para maior produção de estímulos emocionalmente competentes}

Damásio (2003, apud Bispo, 2004) define como estímulos emocionalmente competentes (EEC) aqueles capazes de provocar um estado emocional no sujeito. Esta definição é importante na medida em que Izquierdo (2002, p. 9) afirma que "os maiores reguladores da aquisição, da formação e da evocação das memórias são justamente as emoções e os estados de ânimo".

A atenção é uma das funções mais importantes do sistema nervoso central para o aprendizado. Com ela, podemos, diante de uma variedade de estímulos dos mais diferentes tipos, aos quais somos expostos diariamente, definir o que é mais relevante em determinado momento e focar nossa atenção para aprender algo sobre aquilo que nos instiga. No entanto, nossa capacidade de manter a atenção em determinado estímulo/tema é limitada a um curto período de tempo, por isso a importância de utilizar estímulos de diferentes tipos no processo de aprendizagem. Segundo Guerra (2010, p. 8), “Dificilmente um aluno prestará atenção em informações que não tenham relação com seu arquivo de experiências, com seu cotidiano ou que não sejam significativas para ele".

Além da atenção, outro aspecto extremamente importante para a aprendizagem é a emoção. Isso ocorre porque neurônios que regulam aspectos relacionados aos diferentes tipos de emoção têm conexões diretas com neurônios importantes para a formação de memórias. Neurônios de algumas regiões inclusive acumulam funções de disparo emocional com funções de aprendizagem. Sem dúvida, a presença de emoção favorece a formação de memórias, ou seja, o aprendizado. É muito mais fácil para nós recordarmos um evento ou um conteúdo que aprendemos em um contexto emocional mais intenso do que aqueles aprendidos em um contexto pouco significativo.

Quase todos os tipos de experiências sensoriais ativam instantaneamente diversas partes do cérebro, que associa suas características afetivas (seu caráter agradável ou desagradável; de satisfação ou aversão) e transmite essa informação integrada até centros cerebrais específicos. O cérebro, então, em suas zonas de memória, entre as quais podemos destacar o hipocampo, compara a informação recebida com uma informação prévia, auxiliando no controle da informação que uma pessoa aprenderá ou deixará de aprender, formando o que Izquierdo chama de memória. Em suas palavras: 
Memória é a aquisição, a formação, a conservação e a evocação de informações. A aquisição é também chamada de aprendizagem: só se "grava" aquilo que foi aprendido. A evocação é também chamada de recordação, lembrança, recuperação. Só lembramos aquilo que gravamos, aquilo que foi aprendido. (...) As memórias são feitas por células nervosas (neurônios), são armazenadas em redes de neurônios e são evocadas pelas mesmas redes neurais ou por outras (Izquierdo, 2002, p. 9).

Nesses processos participam diferentes regiões de nosso cérebro, de forma integrada, em que: o hipocampo tem papel reconhecidamente importante na consolidação de novas memórias; o sistema límbico formado por um conjunto de estruturas responsáveis pela ativação e processamento das emoções, como o tálamo, a amígdala, o hipocampo e o hipotálamo, tem relação direta com a formação de memórias; a região cortical frontal permite, entre outras coisas, focarmos nossa atenção em determinados aspectos, além de sua importante função relacionada à linguagem falada e escrita; a região temporal está relacionada à identificação e percepção dos sons; a região occipital reconhece os objetos visualizados, e também é importante para a leitura e o reconhecimento das palavras.

Essas e outras regiões cerebrais atuam interligadas, de maneira que seus neurônios realizam um trabalho conjunto no processo de ensino-aprendizagem. Cabe salientar que essas redes neuronais são complexas e estão sujeitas a constantes modificações, propriedade do sistema nervoso que chamamos plasticidade cerebral/neuroplasticidade, modificações estas que dependem de nossas experiências e vivências. Assim, concordando com Mora (2004), os processos de aprendizagem modificam o cérebro e também o comportamento do sujeito aprendente.

Durante a aprendizagem, os sujeitos envolvidos, por meio das práticas propostas, fornecem estímulos que provocam mudanças nos circuitos neurais, fazendo com que o cérebro se reorganize, gerando aprendizado. Sem dúvida, estratégias pedagógicas que considerem em sua proposta a maneira como o cérebro funciona tendem a ser mais exitosas (Guerra, 2010).

Em face do exposto, a participação dos sujeitos em experiências de investigação para melhor compreensão e conscientização dos temas que estudarão provocará maiores emoções e estímulos do que a visualização de imagens ou, ainda, textos que abordem superficialmente o tema, sem contextualizá-lo. Demonstra-se, assim, a necessidade dos educadores em compreender melhor as possibilidades e limitações da utilização de imagens como recurso pedagógico. Nas palavras de Silveira (2005):

Seja do ponto de vista da semiótica, e das várias abordagens teóricas fundamentadas em códigos, seja do ponto de vista das teorias cognitivas, a imagem tem 
sido amplamente estudada na área de linguagem e comunicação. Entre as vantagens de um texto constituído por imagens, destaca-se o fato de ele ser universal, pois vence a barreira da linguagem falada e escrita, podendo, através de um entendimento imediato, ser compreendido por pessoas de língua e cultura diversas (Silveira, 2005, p. 113).

Salientamos ainda que a utilização da palavra visualização neste texto deve ser entendida como a imagem no nível da ação cognitiva, explicado por Vavra e colaboradores (2011) por meio de duas perspectivas teóricas: teoria de dupla codificação (dual-coding theory - DCT) e hipótese de imagens visuais (visual imagery hypothesis - VIH). Na primeira teoria, Paivio (1986, apud Vavra et al., 2011) e Sadoski e Paivio (2001, apud Vavra et al., 2011) apresentam-nos a visualização como um meio para compreender a maneira na qual as informações linguísticas (palavras e frases) e informações visuais (imagens), codificadas por dois importantes sistemas mentais, funcionam de modo independente, 'um verbal e outro não verbal'. Desse modo, as informações armazenadas em cada sistema podem ser acessadas independentemente uma da outra. No entanto, a combinação de informação linguística e informação visual fornece duplo suporte para a aprendizagem e a aquisição de conhecimentos. Outro importante aspecto da DCT é sua capacidade de oferecer importantes insights sobre como a percepção visual afeta a memória e como a visualização pode ser usada para melhorar a aprendizagem e a compreensão.

A VIH, abordada por Johnson-Laird (1998, apud Vavra et al., 2011) e Pylyshyn (2003, apud Vavra et al., 2011), concentra-se nos objetos de visualização, estes representações gráficas que permitem processar informações de forma mais eficiente do que as verbais, de maneira a reduzir a demanda de memória de trabalho, que tem por função manter a informação ativa no cérebro apenas pelo tempo necessário para determinar se ela deve ou não ser armazenada. A VIH também ressalva uma importante função dos objetos de visualização, o da organização, que torna a informação acessível para manipulação e comparação, gerando inferências e possibilitando a resolução de problemas. De modo geral, Johnson-Laird e Pylyshyn apresentam como premissa básica da VIH os objetos de visualização, como atividades capazes de fornecer as informações e os conceitos necessários para facilitar a aplicação de conhecimentos e habilidades para a resolução de problemas.

Na compreensão desses autores, encontramos a relação entre a IT proposta por Freire e a função epistêmica dos objetos de visualização, quando associados ao contexto dos sujeitos aprendentes. Silveira (2005), ao se posicionar desfavoravelmente à predominância da imagem na civilização atual, justifica que seu excesso contribui para a falta de reflexão lógica dos indivíduos. Assim, os sentidos (re)construídos pelos aprendentes sobre seu 
contexto (que será o contexto em estudo) serão mais significativos na medida em que eles percebem outras relações existentes e as problematizam, procurando perceber o que produz o contexto, o que contribui para que este permaneça como está e as relações socio-historicamente estabelecidas que proíbem esse contexto de mudar - processo grávido de emoções e estímulos favoráveis para aquisição e evocação de memórias.

Nesse sentido, quando o sujeito participa ativamente do processo de IT que será trabalhado, ele recebe mais EEC, porque, ao participar das relações que constituem a situação investigada, seus sentimentos e emoções são mobilizados, o que favorece seu processo de aprendizagem. Carvalho (2007) reforça essa ideia quando afirma que

a emoção e a motivação influenciam na aprendizagem, sendo que os sentimentos, intensificando a atividade das redes neuronais e fortalecendo suas conexões sinápticas, podem estimular a aquisição, a retenção e evocação e articulação das informações no cérebro (Carvalho, 2007, p. 61).

Assim, a escolha das estratégias pedagógicas adotadas no processo de ensino-aprendizagem é fundamental para a (re)construção de sentidos e significados pelos sujeitos que participam do processo - destacando-se que a utilização de recursos multissensoriais ativa múltiplas redes neurais, as quais estabelecem então redes sinápticas entre si (Guerra, 2010). Esse processo começa pela percepção sensorial do contexto, segundo Lent (2001, p. 557): “percepção é a capacidade de associar as informações sensoriais à memória e à cognição, de modo a formar conceitos sobre o mundo, sobre nós mesmos e orientar nosso comportamento". Para ocorrer aprendizagem, essas informações percebidas posteriormente devem ser processadas e interpretadas.

Assim, à medida que as experiências de aprendizado forem repetidas, a memória aprendida será reconsolidada, ou seja, 'fortificada', de forma que as conexões entre os neurônios envolvidos com esse aprendizado serão cada vez mais especializadas. Quanto mais dinâmicas e prazerosas forem essas experiências de aprendizado, maiores serão as alterações na quantidade e na qualidade das conexões sinápticas, afetando assim o funcionamento cerebral e gerando aprendizado - o que converge para a afirmação de Carvalho (2011):

assumir a necessidade de estratégias metodológicas que garantam o desenvolvimento do potencial cognitivo de cada aluno é uma condição para assegurarmos a participação efetiva do mesmo na sociedade (Carvalho, 2011, p. 538).

Partimos então para outro ponto que é essencial nesse processo: a mediação do educador, afirmação ressaltada por Vavra e colaboradores (2011), quando apontam o cuidado que o professor deve ter ao escolher os objetos 
de visualização, a fim de garantir sua relação com o contexto particular de cada situação proposta. Essa consideração vai ao encontro do que queremos enfatizar, ou seja: qualquer que seja a estratégia pedagógica utilizada, seu significado será intencionado e atribuído pelo educador. De acordo com Silva e Bezerra (2001):

uma metodologia de ensino que utilize adequadamente os novos conhecimentos sobre os diferentes tipos de memórias poderá se converter num instrumento auxiliar básico para a cognição. A pedagogia contemporânea necessita utilizar-se das diversas ferramentas disponíveis para subsidiar uma pluralidade de abordagens que promovam a construção de habilidades e competências consoantes com as exigências dos contextos sociais pós-modernos. As novas estratégias de ensino requerem o conhecimento desses processadores cerebrais complexos para que sejam melhor ativados e colocados a serviço da construção de novas aprendizagens Silva e (Bezerra, 2001, p. 5-6).

Nesse sentido, reforçamos o argumento proposto no artigo que, ao apresentar as potencialidades formativas da IT freiriana, a relaciona com utilização de imagens para possibilitar a (res)significação de suas compreensões acerca do contexto. Consideração ratificada por Silveira (2005, p. 124), quando afirma que, além do estímulo visual, "as informações devem ser contextualizadas como premissas de um raciocínio interpretativo para que se atinja um processo de comunicação bem sucedido". Além disso, considerando os aspectos neurobiológicos já discutidos, sem o contexto cognitivo das informações as interpretações de quem aprende serão limitadas, o que vai na contramão de um processo de construção de conhecimento que preza pelo desenvolvimento da consciência crítica.

\section{Considerações finais}

Neste artigo buscamos enfatizar a importância de processos de aprendizagem focados no contexto dos aprendentes e sua potencialidade para gerar EEC, os quais possibilitem o desenvolvimento de sua consciência crítica. Os sujeitos aprendem aquilo que os emociona, que os sensibiliza. Assim, transformar o conteúdo programático de uma disciplina em algo relevante para que o estudante modifique sua realidade é um desafio para o educador. Para a realização da proposta pedagógica que defendemos, apresentamos as etapas do processo de IT, apregoado por Freire, e relacionamos a visualização das imagens construídas no processo de codificação, com hipóteses de teóricos que enfatizam que a combinação de informações linguística e visual, apreendidas no processo de investigação, fornece duplo suporte para a 
aprendizagem e a construção de conhecimentos. Ainda consideramos que a participação dos sujeitos aprendentes durante a pesquisa de informações, pertinentes ao contexto, favorece a ampliação de EEC e, desse modo, sua aprendizagem.

\section{Colaboradores}

Os três autores participaram igualmente de todas as etapas de pesquisa, construção e redação do artigo.

Resumen En el artículo, defendemos el argumento de que la investigación temática propuesta por Freire, al estrechar la relación contenido-cotidiano, favorece la reconstrucción del conocimiento, tomando como base las memorias sociales y culturales. Las memorias transformadas en estímulos emocionalmente competentes, propician una acción docente que fomenta la ampliación de saberes y engramas y, consecuentemente, capacita a los aprendices para la transformación de la realidad. Con esa finalidad, presentamos las ideas freirianas sobre la necesidad ontológica de los humanos de desarrollar la conciencia crítica acerca de sus situaciones existenciales, en base a la investigación temática. En este proceso, lo que se ambiciona es la percepción existencial de los individuos, de modo que, tomando distancia de la situación en que se encuentran, puedan elaborarla como una imagen, cuadro o diapositiva, sobre la cual se puede problematizar, discutir y replicar para transformar. En la secuencia de esta actitud educativa, discutimos las bases neurobiológicas, o sea, cómo el cerebro interpreta, comprende y aprehende las informaciones de los contextos investigados y presentamos algunas ideas sobre estímulos emocionalmente competentes y el proceso de aprendizaje.

Palabras clave educación; Paulo Freire; estímulos emocionalmente competentes; neurociencias. 


\section{Notas}

1 Universidade Federal do Pampa, Uruguaiana, Rio Grande do Sul, Brasil.

Doutoranda em Educação em Ciências na Universidade Federal do Rio Grande.

<dianafreitas@unipampa.edu.br>

Correspondência: Laboratório de Estresse, Memória e Comportamento, Universidade Federal do Pampa, Campus Uruguaiana, BR-472, km 592, Caixa Postal 118, CEP 97500-970, Uruguaiana, Rio Grande do Sul, Brasil.

2 Universidade Federal do Rio Grande, Rio Grande, Rio Grande do Sul, Brasil. Mestrando em Educação em Ciências da Universidade Federal do Rio Grande. <cezarsmott@gmail.com>

3 Universidade Federal do Pampa, Uruguaiana, Rio Grande do Sul, Brasil. Pós-doutorado em Neurofisiologia pela Katholieke Universiteit Leuven (Bélgica) e doutorado em Fisiologia pela Universidade Federal do Rio Grande do Sul.

<pamelacarpes@unipampa.edu.br>

4 A 'consciência real' em The human science and philosophy, de L. Goldman (1969), são as 'soluções praticáveis percebidas' e as 'soluções efetivamente realizadas', que estão em oposição à 'consciência possível', às 'soluções praticáveis desapercebidas', o que Freire (2011) chama de 'inédito viável'.

\section{Referências}

BISPO, Ronaldo. Flash Aesthesis: uma neurofilosofia da experiência estética. Trans/form/ação, São Paulo, v. 27, n. 2, p. 113-142, 2004.

CARVALHO, Fernanda A. H. de. Reaprender a aprender: a pesquisa como alternativa metacognitiva. 150f. Tese (Doutorado em Educação) - Faculdade de Educação, Pontifícia Universidade Católica do Rio Grande do Sul, Porto Alegre, 2007.

CARVALHO, Fernanda A. H. de. Neurociências e educação: uma articulação necessária na formação docente. Trabalho, Educação e Saúde, Rio de Janeiro, v. 8, n. 3, p. 537-550, nov. 2010/fev. 2011.

FIORI, Ernani M.. Prefácio. In: FREIRE, Paulo. Pedagogia do oprimido. 50. ed. Rio de Janeiro: Paz e Terra, 2011.
FREIRE, Paulo. Pedagogia da esperança: um reencontro com a pedagogia do oprimido. 13. ed. Rio de Janeiro: Paz e Terra, 1997.

FREIRE, Paulo. Pedagogia da autonomia: saberes necessários à prática educativa. 40 . ed. Rio de Janeiro: Paz e Terra, 2009.

FREIRE, Paulo. Pedagogia do oprimido. 50. ed. Rio de Janeiro: Paz e Terra, 2011.

GOLDMAN, Lucien. The Human Science and Philosophy. Londres: The Chancer Press, 1969.

GUERRA, Leonor B. Como as neurociências contribuem para a educação escolar? FGR em Revista, Belo Horizonte, v. 4, n. 5, p. 6-9, 2010.

IZQUIERDO, Iván. Memória. Porto Alegre: Artmed, 2002. 
LENT, Robert. Cem bilhões de neurônios: conceitos fundamentais da neurociência. São Paulo: Atheneu, 2001.

MORA, Francisco. Como funciona o cérebro. Porto Alegre: Artmed, 2004.

SILVA, Mário M. da; BEZERRA, Edileuza de L. Contribuições das neurociências ao processo de ensino-aprendizagem. COLÓQUIO INTERNACIONAL EDUCAÇÃO E CONTEMPORANEIDADE, 5. São Cristóvão, p. 1-16, 2011. Anais... Disponível em: <http://educonse.com. br/2011/cdroom/eixo\% 2014/PDF/Microsoft $\% 20$ Word $\% 20-\%$ 20CONTRIBUICoES $\% 20$ DAS \%20NEUROCIeNCIAS.pdf > . Acesso em: 15 mar. 2013.
SILVEIRA, Jane R. C. da. A imagem: interpretação e comunicação. Linguagem em (Dis)curso, Tubarão, v. 5, p. 113-128, 2005.

VAVRA, Karen L. et al. Visualization in Science Education. Science Education Journal Alberta, Alberta, v. 41, n. 1, p. 22-30, 2011.

Recebido em 06/05/2013

Aprovado em 13/06/2013 